This is a self-archived version of an original article. This version may differ from the original in pagination and typographic details.

Author(s): Zeeshan, Khaula; Neittaanmäki, Pekka

Title: Internet of things Enabling Smart School : An Overview

Year: 2021

Version: Accepted version (Final draft)

Copyright: @ 2021 IEEE

Rights: In Copyright

Rights url: http://rightsstatements.org/page/InC/1.0/?language=en

Please cite the original version:

Zeeshan, K., \& Neittaanmäki, P. (2021). Internet of things Enabling Smart School : An Overview. In HONET 2021 : IEEE 18th International Conference on Smart Communities : Improving Quality of Life Using ICT, IOT and AI. IEEE. IEEE International Conference on Smart Communities.

https://doi.org/10.1109/honet53078.2021.9615391 


\section{Internet of things Enabling Smart School: An Overview}

\author{
$1^{\text {st Khaula Zeeshan }}$ \\ Faculty of Information Technology \\ University of Jyväskylä \\ Jyväskylä, Finland \\ khaula.k.zeeshan@student.jyu.fi
}

\author{
$2^{\text {rd }}$ Pekka Neittaanmäki \\ Faculty of Information Technology \\ University of Jyväskylä \\ Jyväskylä, Finland \\ pn@jyu.fi
}

\begin{abstract}
Internet of things (IoT) is making its way in every field of life. Education is not an exception. IoT is making landmark achievements in its applications in the field of education. This paper presents an overview of the key IoT applications in the field of education from the perspective of school management, teachers, and learners enabling smart school concept and challenges and limitations in embarking IoT in educational settings.
\end{abstract}

Index Terms - Internet of things, smart school, education, digital applications

\section{INTRODUCTION}

Newfangled technologies are making their way in our daily lives beyond our expectations. In last decade, technology and digitization has changed the world we live in. Unanticipated advancements in wireless technologies and digital devices has led a technology revolution around us. In that scenario, industrial revolution is bringing automation in every corner of life including education. At this point of advancement, it is very crucial to think of inclusive, equitable, quality education. World is divided in two halves, the advanced and highly developed part of the globe and underdeveloped, poor economies of the globe. We have to think how advancement in technology can help in upbringing of underdeveloped world. IoT is one of the revolutionary technologies which can be embedded in educational settings to improve educational quality, learner's performance, facilitation of learning and in-campus management. IoT can equip students, teachers, and school management with tools to enhance their working with quality and progress.

This paper first provides introduction to IoT, then presents an overview of application of IoT in education. We showcased the areas in educational settings where IoT can be used to deliver a smart school concept based on most recent research. Finally, paper presents limitations and challenges in adapting IoT solutions in educational settings.

\section{INTERNET OF THINGS, IOT}

The term internet of thing was first used by the cofounder of the Auto-ID Center at the Massachusetts Institute of Technology (MIT), named Kevin Ashton in 1999 [1]. A more comprehensive definition of Internet of Things is later given by International Telecommunications Union (ITU), "As enabling advanced services by interconnecting (physical and virtual) things based on existing and evolving interoperable information and communication technologies" (International Telecommunications Union, 2012) [2]. Internet of things is a technology which works in combination of other technologies. For example IoT makes use of wireless communication and artificial intelligence in many situations and deliver the tasks.A thing acting as a thing of internet should be capable of gathering and transmitting data to other connected devices. Therefore, an object or thing of internet must be capable of interacting with action-based responses. Additionally the IoT object/device must be capable of receiving information. Therefore, a thing of IoT collects and transfer data, interact with other devices, receives information and enables fast communication.

IoT architecture is based on four layers as shown in Figure1. Physical layer serves as the first layer. Physical layer constitutes of radio frequency identification tags (RFID) tags, sensors and acutators. These devices acts as data gathering objects. They can be wired or connected through wireless. Then comes the second layer, known as network layer. Network layer constitutes wireless, wired networks and cloud. A software layer or data processing layer then acts as an engine to process all collected data. This layer constitutes of data bases, data processing units and high power data processing servers to process data. Hence, processing layer enables the communication protocol for the communication and management of data, thus enabling an IoT application/tool to work. Finally comes the application layer, which enables machine to machine (M-M) and machine to human (M-H) interaction utilizing smart devices. Application layer behaves as an interface between third party applications and infrastructure.Therefore, IoT helps humans to gather information, learn meaningful data and act accordingly.

\section{IOT IN EDUCATION: SMART SCHOOL}

Education sector can leverage from IoT in most effective way. Literature study has shown that IoT has diverse applications in the educational field for teachers,learners and school managers. In this section we are presenting an overview of possible applications of IoT in school settings mentioned in literature work. The concept of smart schools that is, ICT 


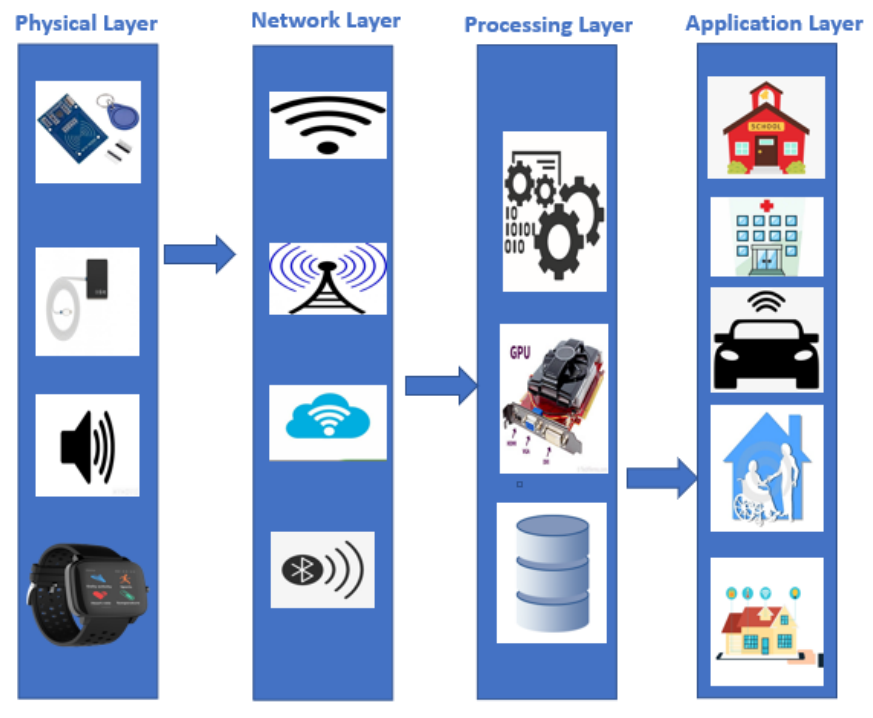

Fig. 1. IoT Architecture

driven schools is not new but still in its infancy stage. Focus of this section is that how IoT can deliver to bring smart school concept in reality?

\section{A. IoT for smart school management}

- Energy management: Smart energy management system requires Interconnectivity and interoperability. In smart school scenario, cost effective energy saving and management would benefit school organization largely. School organization can save hundreds of dollars per month by enhancing smart utility of energy. For example, electrical energy can be used on demand. Sensors in school facility could facilitate on demand usage of electrical energy and could turn off extra appliances when not in use. Therefore, minimizing carbon footprint and cost per unit of electricity used. Energy-related information among the users and management system in a school facility can be provided by an IoT-based communication framework. A study [3] has developed IoT based energy-management platform. Such platform can facilitate the development of a demand response (DR) energy management system.

- School Premises Security: School premises security is an important smart school feature powered by IoT. Most schools lack the secured infrastructure which can detect and identify abuse, sexual assault, theft, fire, and other accidents that can occur within the school premises. Real time camera recording the scenes connected with IoT sensors and devices enables school management to keep an eye on the school premises and identify accident scene and initiate action plan immediately if needed. The research work in [4] proposed IoT based alert mechanism named secure system of Internet of school things (SIoST).This system uses advanced communication system based on $5 \mathrm{G}$ cellular technologies, intelligent transportation systems, sensing technologies, and IoT networks.
- Management of students with special needs: Students with hearing, vision, mental illness and learning disabilities need holistic and diverse solutions to facilitate them in learning. IoT can create a user friendly and customized environment for students with special needs. For example, a system of sensor-connected gloves and a tablet to generate verbal speech, translated from sign language which the teachers can use and deaf and mute students can take advantage of this system in class communication. Different research studies discussed the scope and application of IoT for students with special needs [5] [6] [7].Some examples of assistive technologies for students with disabilities are Screen reader, which is text-to-speech application that reads out computer and internet related information to assist people who are blind or vision impaired, on-screen keyboard helps students with mobility impairments to type, screen magnifier for enlarging screen content, and On-screen alerts can send Visual messages to help deaf or hearing impaired people [8].

- Smart school transport: IoT solution can provide school management with a smart transport system to operate for student's transportation. In a study [9], an IoT based vehicle monitoring system is presented. The proposed system consists of a mobile phone application and a microcontroller. The position of the school bus is determined from a device using global positioning system (GPS).The system deployed alcohol sensor and a panic switch for securing the security of the children. This smart transport system provides parents and school management the real time status of the bus.

- Student's health monitoring system: For any educational institution, its student's performance is of prime importance. A student's performance is highly effected by his/her health issues. If a student is going through any sickness, or psychlogical problems he/she can not focus on their studies and therefore results in poor academic performance. Sensors collect a large number of health data. IoT alongwith cloud collect and process huge data to measure student's health and wellbeing. In study [10] an Ambient Intelligence assisted Health Monitoring System (AmIHMS) with IoT devices has been proposed for students health monitoring. Research work in [11] suggested cloud-centric IoT based student health monitoring framework. Another research study [12] focused on emotion detection using Long Short-Term Memory (LSTM) using physiological signals. Researchers proposed here an IoT framework for healthcare and distance learning in pandemic era.

\section{B. IoT for Teachers}

- Autonomous attendance system: Taking attendance of each student is an hectic and time consuming task for teachers. Teachers need to focus on their primary task which is teaching and facilitating learners in learning. Automated attendance system based on biometric atten- 
dance or barcode with an Identity card number can be used at the entrance of the classroom door. So each student entering from the door will be registered. This information can be shared with the parents as well so they know that their kid is in class or not. Similarly, there are studies suggesting automated attendance system utilizing IoT in combination with face recognition technology [13] [14] [15].

- New pedagogies: With the advancements in technologies, the concept of classroom is changed now. Modern day classrooms are free of physical space and traditional ways. Modern world classrooms offers new ways of learning and therefore, teachers are facilitating learners with a new set of pedagogies which are driven by digital technologies and digital learning environments.Therefore, nurturing digital pedagogies, which means that how teacher can most effectively takes benefit of the certain technology for teaching and learning facilitation. One such example is flipped classroom where teacher has applied flipped classroom as IoT element while teaching computer networks [16].

- Feedback and assessment systems: IoT based embedded assessment tools are quick and easy ways to look into student's performance and make assessment on the bases of student's engagement, interaction, participation and task completion. A study proposed IoT based students interaction framework using attention scoring assessment in e-Learning [17]. Similarly, another research work suggested IoT based real time data mining approach for students assessment [18]. In research work [19] Rasberry pie and IoT is udsed for student's engagement assessment.

- IoT for STEM education: Science,technology, engineering and mathematics education demands hands on learning experience in labs and requires measurements, observations, experiments performing in laboratories. IoT sensors and devices has made it possible to not only provide real time measurements but also the analysis of the data collected. Another advantage of Iot is that the the STEM students can use IoT kits for project based learning to harness STEM skills like design thinking [20]. A study presented that how IoT applications can be applied to Physics experimental class [21]. Research in [22] showcased how IoT can be integrated in STEM education and discussed a case study of IoT integration for embedded system course.

\section{IoT for Learners}

- Distance learning: Covid era has proved online learning modes as concrete and effective learning ways. When the schools around the world were locked, the students around the world were having their schools right in their homes. Thanks to the digital advancements in educational sector. Distance learning which can be of any form, online learning, mobile learning, virtual classroom, hybrid learning or e-learning. All such forms comes

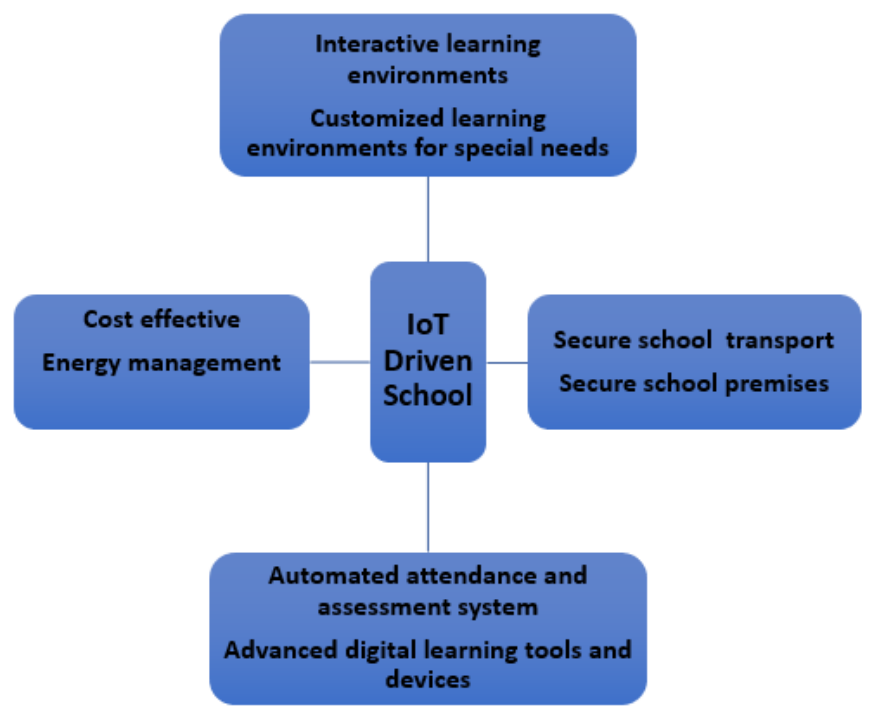

Fig. 2. IoT Driven Smart School

under distance learning. IoT has the capability to enhance distance learning effectively. One such example is that, a study presented that IoT in distance learning allows to increase the learning efficiency up to 20 percent. IoT devices during the video lesson monitored the level of the brain activity and sending the feedback to the software program. Digital image and video stream are modulated with the signals which switch the brain into the active state. IoT detects the time of tiredness and sends signals to keep brain active [23]. In this way, IoT monitors and the brain activity and also activate it.

- Enhaced productivity and interaction: Smartphone-based online classes, virtual classes or e-classes develops more interactivity and engagement among students. This interaction-based learning develops students interest in involving different tasks and participate actively in feedback, and assessment process. Therefore, IoT based learning environments enhance students productivity and interaction. For example, e-books with barcodes helps students read in an interactive environment. Scanmaker is an IoT device which can quickly scan editable text from books, papers and other documents directly into a phone, tablet or computer. The device has the ability to translate text in 40 languages [24].

- Personalized digital learning environments: A digital learning environment provides a personalized learning experience. One such example is Blackboard [25], offers virtual classroom technology with increased collaboration, interactive learning management system (LMS), and websites to keep parents, students and others updated with the latest grades, attendance, events and news. 


\section{BOTTLENECKS IN IOT ADAPTATION IN EDUCATIONAL SETTINGS}

Apart from many benefits of incorporating IoT in education, there are some challenges or risks associated with it too [26]. This section discusses the main risks/challenges associated with IoT adaptation in education.

\section{A. Security and Privacy}

The presence of highly advanced technologies connected to internet poses threats of cyber attacks. Students or outsiders can easily attack on their learning institutions. There are also chances that institutes can be made nonfunctional by controlling their systems. It also can happen that failure in connectivity can stop the whole system to work. Data breaches remains the huge security concerns. There are security challenges related to authentication, integrity, end to end security and confidentiality [27].

Advanced IoT devices and sensors in combination with different technologies like RIFD, NFC, 4G, 5G collect huge amount of data. There is great concern about that data. Where does that data go? Who takes benefits of this data or control data? These are the questions related to privacy when it comes to internet technologies which collect huge personal data [28]. The future of IoT adaptation in educational sector can only be ensured if the security issues associated with it are addressed.

Confidentiality is an important factor in IoT security as the data collected should be available to only authenticated users. Users can be humans and machines and for IoT confidentiality, it is important that data should not be leaked to unauthorized users, whether they are machines or humans.

Large amount of data management is another security concern as IoT is collecting and processing huge data, therefore a foolproff data management system is required. Data can be leaked, tempered or lost during the process of transmission from one sender to another. Therefore, a secured data management system is required to avoid any data mismanagement and breach.

\section{B. Scalability and Reliability}

Scalability is a great concern in educational setting. While applying IoT applications, huge data will be gathered. Incorporating IoT in education will generate a large volume of data. Therefore, there is a great need of data analysis to seek indepth insights into data. Hence, data scalibility is a bottleneck in IoT application in educational settings. In research [29], scalability is discussed and the research proposed a social recommender system based on hadoop and parallel computing to provide students with personalized learning content on the basis of huge data analysis.

A study [30]proposed secured and scalable IoT system based on secret sharing scheme. The studey also suggested that scalability and reliability of IoT system can be achieved by deploying distributed IoT infrastructure.

Scalability issue is also concerened when the IoT based solutions are not sustainable. There should be equal availability of such technologies to all classes of society. Moreover, schools should have enough budget to buy these services and have sustainable system running smoothly.

\section{Dehumanization and ethical concerns}

Technology is great to have in our daily lives, but it should not be at the cost of humanization and ethics. Indeed, technology here to play holistic roles to make our lives easy, but we should devise an operating protocol for any technology to work. Dehumanisation is one main issue which would arise when systems will work at their own and there will be less human involvement. Excessive machine to machine interaction may minimize human control and shift control and power to the organisations which own these services [31]. Therefore, there is a great chance of unethical and unjustful distribution of power.

User awareness is another important factor to take into account. Users must be aware of attack risks and they should be educated how to protect themselves from internet vulnerability. Governments should not only devise a mechanism for security standards but should also organise mass awareness and education about these technologies and their usage for the technology users.

\section{CONCLUSION}

Education enabled by advanced technologies can uplift economies. Internet of Things is one such technology, which can revolutionize the traditional school set up and enable smart school concept. Our research here has presented an overview of IoT applications in school setting. IoT has multifaceted benefits in educational settings. Therefore, we suggest that technology driven education can provide quality education with equity and inclusivity. However, there comes challenges too with technology and therefore, the use of technology should be sustainable, scalable and ethical to minimize the bottleneck effects.

\section{REFERENCES}

[1] T. Mitew, "Do objects dream of an internet of things?" The Fibreculture Journal: Digital Media + Networks + Transdisciplinary Critique, 23. Retrieved from http://fibreculturejournal.org/wp-content/pdfs/FCJ168Teodor

[2] International Telecommunications Union, Internet of Things Global Standards, 2012 Initiative. Retrieved from http://www.itu.int/en/ITUT/gsi/iot/Pages/default.aspx

[3] M. Wei, S. H. Hong, M. Alam, "An IoT-based energy-management platform for industrial facilities", Applied Energy, Vol. 164, pp. 607619,2016

[4] K. N. Qureshi, A. Naveed, Y. Kashif, and G. Jeon, ”Internet of Things for education: A smart and secure system for schools monitoring and alerting", Computers and Electrical Engineering, Vol. 93, 107275, ISSN 0045-7906, 2021. https://doi.org/10.1016/j.compeleceng.2021.107275.

[5] N. S. Mala, S. S. Thushara and S. Subbiah, "Navigation gadget for visually impaired based on IoT," 2017 2nd International Conference on Computing and Communications Technologies (ICCCT), 2017, pp. 334338, doi: 10.1109/ICCCT2.2017.7972298.

[6] M. A. Rahman, M. S. Sadi, "IoT Enabled Automated Object Recognition for the Visually Impaired", Computer Methods and Programs in Biomedicine Update, Vol. 1, 2021, 100015, ISSN 2666-9900, https://doi.org/10.1016/j.cmpbup.2021.100015.

[7] M. Bansal, S. Garg, "Internet of Things (IoT) based Assistive Devices,' 6th International Conference on Inventive Computation Technologies (ICICT), 2021, pp. 1006-1009, doi: 10.1109/ICICT50816.2021.9358662. 
[8] S.Hollier,"Affordable access",2016. Retrieved from http://www.affordableaccess.com.au

[9] M. V. Vyavahare, "IoT based school bus monitoring and security system", International Journal of Innovative Science and Research Technology, Vol. 4, Issue 3, 2019.

[10] L. Hong-tan, K. Cui-hua, B. Muthu, and C.B. Sivaparthipan, "Big data and ambient intelligence in IoT-based wireless student health monitoring system", Aggression and Violent Behavior,101601, ISSN 1359-1789, 2021. https://doi.org/10.1016/j.avb.2021.101601.

[11] P. Verma, S.K. Sood and S. Klara, "Cloud-centric IoT based student healthcare monitoring framework",J Ambient Intell Human Comput 9, 1293-1309, 2018. https://doi.org/10.1007/s12652-017-0520-6

[12] M. Awais, M. Raza, N. Singh, K. Bashir, U. Manzoor, S. U. Islam, and, J. J. P. C. Rodrigues, "LSTM based Emotion Detection using Physiological Signals: IoT framework for Healthcare and Distance Learning in COVID-19”, IEEE Internet of Things Journal,2020. DO - 10.1109/JIOT.2020.3044031

[13] S. Patel, P. Kumar, S. Garg, and, R. Kumar, "Face Recognition based smart attendance system using IOT", international Journal of Computer Science and Engineering", Vol. 6, Issue-5, 2018.

[14] T. Sharma and S. L. Aarthy, "An automatic attendance monitoring system using RFID and IOT using Cloud," Online International Conference on Green Engineering and Technologies (IC-GET), 2016, pp. 1-4, 2016. doi: 10.1109/GET.2016.7916851.

[15] R. Kariapper, "Attendance system using RFID, IoT and Machine learning: A two factor verification approach" Systematic Reviews in Pharmacy, Vol. 12, pp.314-321, 2021.

[16] Z. Azamat, Y. Seong-Moo, S. Zhulduz, and Z. Meirambek, "Implementation and Evaluation of Flipped Classroom as IoT Element into Learnng Process of Computer Network Education", International Journal of Information and Communication Technology Education, Vol. 14, pp. 30-47, 2018.

[17] M. Farhan, S.Jabbar, M. Aslam, M.Hammoudeh, M. Ahmad, S. Khalid, M. Khan, and K. Han, "IoT-based students interaction framework using attention-scoring assessment in eLearning, Future Generation Computer Systems, Vol.79, pp. 909-919, ISSN 0167-739X, 2018. https://doi.org/10.1016/j.future.2017.09.037.

[18] M. Farhan, S. Jabbar, and M. Aslam, "A Real-Time Data Mining Approach for Interaction Analytics Assessment: IoT Based Student Interaction Framework". Int J Parallel Prog, pp. 886-903, 2018. https://doi.org/10.1007/s10766-017-0553-7

[19] S. Mahmood, S. Palaniappan, R. Hasan, K. U. Sarker, A. Abass and P. M. Rajegowda, "Raspberry PI and role of IoT in Education,"4th MEC
International Conference on Big Data and Smart City (ICBDSC), pp. 1-6, 2019. doi: 10.1109/ICBDSC.2019.8645598.

[20] M. Kusmin, M. Saar and M. Laanpere, "Smart schoolhouse — designing IoT study kits for project-based learning in STEM subjects," IEEE Global Engineering Education Conference (EDUCON), pp. 1514-1517, 2018. doi: 10.1109/EDUCON.2018.8363412.

[21] I. Irwandi, I. M. Sari, R. Oktavia, and M. Syukri, "MEMS and IoT Applications in ISLE-based STEM Physics Learning Media for Mechanics Topic with LabVIEW Integration. Journal of Physics: Conference Series. 1462. 012066. 10.1088/1742-6596/1462/1/012066, 2020.

[22] J. He, D. Chia-Tien , Y. Xie and J. Lartigue, "Integrating Internet of Things (IoT) into STEM undergraduate education: Case study of a modern technology infused courseware for embedded system course," IEEE Frontiers in Education Conference (FIE), pp. 1-9, doi: 10.1109/FIE.2016.7757458, 2016.

[23] R. Yakoubovsky, and V. Sarian, "IoT in Effective Distance Learning Process,"1st International Conference on Technology Enhanced Learning in Higher Education (TELE), pp. 311-314, 2021. doi: 10.1109/TELE52840.2021.9482488

[24] Scanmaker, "The digital highlighter". https://scanmarker.com/

[25] Blackboard, "Virtual classroom solution". https://www.blackboard.com/

[26] M.Georgescu, and D.Popescu, "How could internet of things change the E-learning environment", The 11th International Scientific Conference eLearning and Software for Education, 2015.

[27] T. Yousuf, R. Mahmoud, F. Aloul, I. Zualkernan, "Internet of Things (IoT) Security: Current Status, Challenges and Countermeasures", International Journal of Information Security Reserach (IJISR), Vol. 5, Issue-4, 2015

[28] R. Mahmoud, T. Yousuf, F. Aloul and I. Zualkernan, "Internet of things (IoT) security: Current status, challenges and prospective measures," 2015 10th International Conference for Internet Technology and Secured Transactions (ICITST), pp. 336-341, 2015. doi: 10.1109/ICITST.2015.7412116.

[29] A.Jagtap, B. Bodkhe, B. Gaikwad, and and S. Kalyana, "Homogenizingsocial networking with smart education by means of machine learning and Hadoop: A case study", In International Conference on Internet ofThings and Applications (IOTA), pp. 85- 90, 2016

[30] H. Jiang, F. Shen, S. Chen, K. C. Li, and Y.S.Jeong, "A secure and scalable storage system for aggregate data in IoT", Future Generation Computer Systems, Vol. 49, pp. 133-141, ISSN 0167-739X, 2015. https://doi.org/10.1016/j.future.2014.11.009.

[31] M.Kassab, J.F. DeFranco, P.A. Laplante,"A Systematic Literature Review on Internet of Things in Education: Benefits and Challenges" Journal of Computer Assissted Learning, 2020. DOI:10.1111/jcal.12383. 